\title{
Supercapacitors Based on Nickel Oxide/Carbon Materials Composites
}

\author{
Katarzyna Lota, ${ }^{1}$ Agnieszka Sierczynska, ${ }^{1}$ and Grzegorz Lota ${ }^{1,2}$ \\ ${ }^{1}$ Central Laboratory of Batteries and Cells, Institute of Non-Ferrous Metals Branch in Poznan, Forteczna 12, 61-362 Poznan, Poland \\ ${ }^{2}$ Institute of Chemistry and Technical Electrochemistry, Poznan University of Technology, Piotrowo 3, 60-965 Poznan, Poland
}

Correspondence should be addressed to Grzegorz Lota, grzegorz.lota@put.poznan.pl

Received 3 August 2010; Revised 25 September 2010; Accepted 22 October 2010

Academic Editor: Shen-Ming Chen

Copyright (C) 2011 Katarzyna Lota et al. This is an open access article distributed under the Creative Commons Attribution License, which permits unrestricted use, distribution, and reproduction in any medium, provided the original work is properly cited.

\begin{abstract}
In the thesis, the properties of nickel oxide/active carbon composites as the electrode materials for supercapacitors are discussed. Composites with a different proportion of nickel oxide/carbon materials were prepared. A nickel oxide/carbon composite was prepared by chemically precipitating nickel hydroxide on an active carbon and heating the hydroxide at $300{ }^{\circ} \mathrm{C}$ in the air. Phase compositions of the products were characterized using X-ray diffractometry (XRD). The morphology of the composites was observed by SEM. The electrochemical performances of composite electrodes used in electrochemical capacitors were studied in addition to the properties of electrode consisting of separate active carbon and nickel oxide only. The electrochemical measurements were carried out using cyclic voltammetry, galvanostatic charge/discharge, and impedance spectroscopy. The composites were tested in $6 \mathrm{M} \mathrm{KOH}$ aqueous electrolyte using two- and three-electrode Swagelok systems. The results showed that adding only a few percent of nickel oxide to active carbon provided the highest value of capacity. It is the confirmation of the fact that such an amount of nickel oxide is optimal to take advantage of both components of the composite, which additionally can be a good solution as a negative electrode in asymmetric configuration of electrode materials in an electrochemical capacitor.
\end{abstract}

\section{Introduction}

Electrochemical capacitors have generated great interest because of their possible use in high power applications such as lasers and for propulsion in electric vehicles. There are a number of electrode materials being developed for electrochemical capacitors. The main electrode materials are microporous activated carbons with high specific areas, which take advantage of capacitance arising from charge separation at an electrode/electrolyte interface and can be used with either aqueous or organic electrolytes [1-3]. However, new trends for supercapacitors development are connected with the application of the materials with pseudocapacitance properties associated with fast and reversible surface redoxtype reactions using, for example, transition metal oxides or conducting polymers $[4,5]$. To utilize both the advantage of double-layer capacitance and pseudocapacitance, many composite materials consisting of active carbon and metal oxide have been investigated as electrode materials for electrochemical capacitors [6-12]. Recent research has focused on cheap transition metal oxides. The $\mathrm{NiO}$ materials have generated great interest because of the low cost of their raw materials, low toxicity, and being an environmentally friendly character. Nickel oxide has many other possible applications, for example, as a catalyst, an electrochromic film, or a gas sensor. Unfortunately, $\mathrm{NiO}$ electrodes have high resistivity, which is a serious drawback to apply for a practical application to supercapacitors. The supercapacitor electrodes with $\mathrm{NiO}$ could be obtained using both methods: chemical and electrochemical [8-12]. The route of preparation leads to formation of various morphologies of nickel oxide, which has an influence on the electrochemical properties of the material. The highest value of capacity is obtained for nickel oxide prepared as a thin film $[10,13,14]$. A quite good capacitive behavior is exhibited by nickel oxide with nanoflake morphology [15]. The porous nickel oxide is also considered as electrode material for asymmetric capacitors $[16,17]$.

In our work, composites with different proportions of nickel oxide/carbon material were prepared. Nickel oxide 


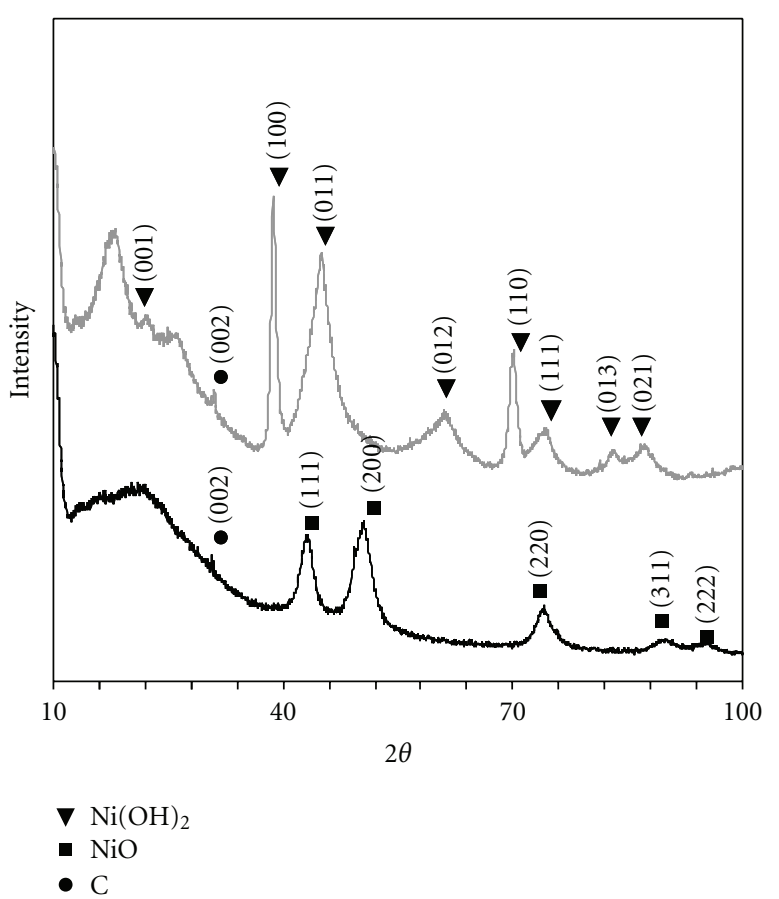

FIGURE 1: XRD pattern of the deposited nickel hydroxide on AC and nickel oxide on AC.

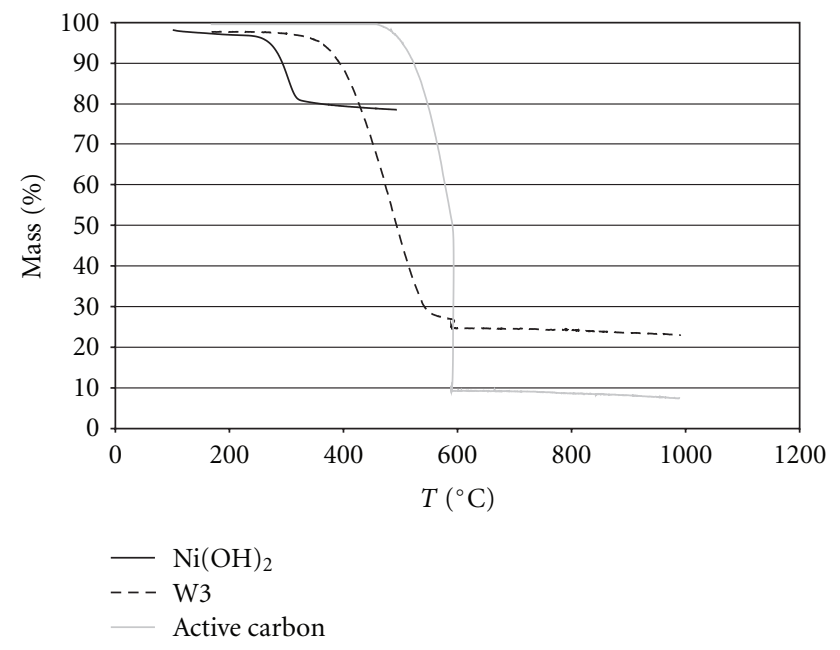

Figure 2: TGA curves of NiO, W3, and active carbon.

was prepared by chemically precipitating nickel hydroxide on carbon active and heating the hydroxide in the air in $300^{\circ} \mathrm{C}$. We studied electrochemical performances of composite electrodes used in electrochemical capacitors in addition to the properties of electrode consisting of separate active carbon and nickel oxide only. During the galvanostatic charge/discharge, the potentials of positive and negative electrodes were measured. As a result, the range of operating voltage for both electrodes was estimated. It was shown that operating voltage for positive and negative electrodes is not equal.

\section{Experimental}

A nickel oxide/carbon composite was prepared by direct chemical precipitation of nickel hydroxide on active carbon (AC) NORIT SX2 (POCH-Poland) from the $0,5 \mathrm{M} \mathrm{Ni}\left(\mathrm{NO}_{3}\right)_{2}$ solution. The active carbon was suspended in $100 \mathrm{~mL}$ of nickel salt using a supersonic washing glove. $1 \mathrm{M} \mathrm{NaOH}$ solution was slowly dropped into the above mixed solution; the molar ratio of $\mathrm{Ni}\left(\mathrm{NO}_{3}\right)_{2} / \mathrm{NaOH}$ was $1: 2$. The temperature of the precipitation process was about $60^{\circ} \mathrm{C}$. The mixed solution was stirred for $1 \mathrm{~h}$. The precipitated materials were washed with distilled water and then dried at $80^{\circ} \mathrm{C}$. Then composites or nickel hydroxide was heated at $300^{\circ} \mathrm{C}$ in the air for 2 hours. The composition of $\mathrm{NiO} / \mathrm{C}$ composites was estimated from mass difference after both processes: chemical precipitation of nickel hydroxide and calcinations of composites.

Phase compositions of the products were characterized by an X-ray diffraction (XRD) analysis using $\mathrm{CuK} \alpha$ radiation. The precipitated materials after calcination were characterized by a thermogravimetric analysis (TGA) using STA 409 (Netzsch) and scanning electron microscopy (SEM EVO40 ZEISS). Specific surface area measurements were performed using ASAP $2010 \mathrm{M}$ (Micromeritics). The capacitor electrodes were formed as pellets consisting of $85 \%$ active material, 10\% binder (PVDF, Kynar Flex 2801), and 5\% acetylene black (to ensure good conductivity). Electrodes were prepared in the form of pressed pellets $(12-15 \mathrm{mg})$. The composites were tested in $6 \mathrm{M} \mathrm{KOH}$ aqueous electrolyte using two- and three-electrode Swagelok system. For the measurements in three-electrode system, the $\mathrm{Hg} / \mathrm{HgO}$ electrode immersed in $6 \mathrm{M} \mathrm{KOH}$ was used as a counter electrode. The specific capacities of electrode materials have been obtained using three techniques: cycling voltammetry (1-100 $\left.\mathrm{mVs}^{-1}\right)$, galvanostatic charge/discharge $\left(50 \mathrm{mAg}^{-1}\right.$ $\left.5 \mathrm{Ag}^{-1}\right)$, and impedance spectroscopy $(100 \mathrm{kHz}-1 \mathrm{mHz})$ using AUTOLAB ECOCHEMIE BV-PGSTAT 30/FRA2 and ARBIN Instruments BT2000. The capacitance values were calculated per active mass of one electrode.

\section{Results and Discussion}

3.1. Characterization of Composites. Composites with different ratios of nickel oxide to carbon material were prepared. They are labelled as: $\mathrm{W} 1$ (34 wt.\% $\mathrm{NiO}$ and 66 wt.\% AC), W2 (17 wt.\% $\mathrm{NiO}$ and 83 wt.\% AC), and W3 (7 wt.\% $\mathrm{NiO}$ and 93 wt.\% AC). Compositions of electrode materials were characterized by an X-ray diffraction (XRD) analysis. Figure 1 shows the XRD pattern of the deposited nickel hydroxide $\left(\beta-\mathrm{Ni}(\mathrm{OH})_{2}\right)$ and nickel oxide $(\mathrm{NiO})$ on active carbon (W1) before and after the calcination process. The calcination process has an influence on the increase of crystallinity. During the calcination process from room temperature to $200^{\circ} \mathrm{C}$, hydrated water is lost. Next, at $300^{\circ} \mathrm{C}$ nickel hydroxide is converted into nickel oxide and water [12]. The thermal stability of composite W3 and pristine materials was investigated by TGA. Figure 2 shows the result of TGA. The result illustrates that the carbon active is thermally stable up to $470^{\circ} \mathrm{C}$. In the second stage (470$590^{\circ} \mathrm{C}$ ), the weight of the products dropped dramatically, and 


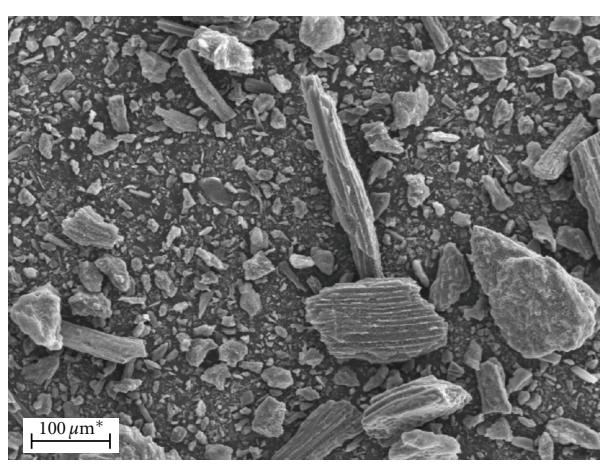

(a)

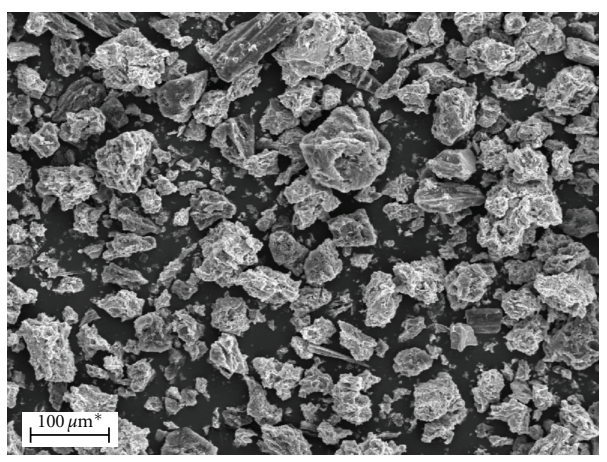

(c)

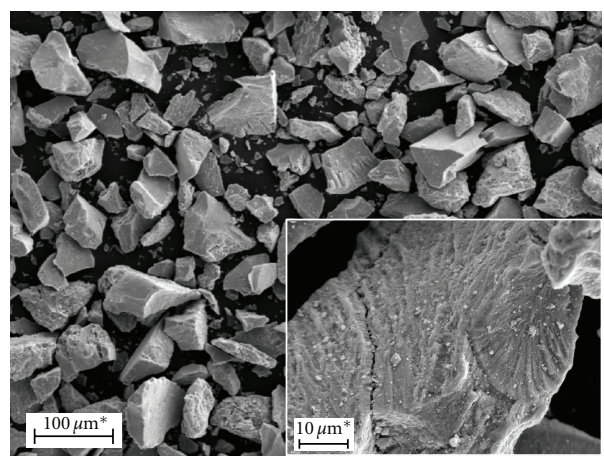

(b)

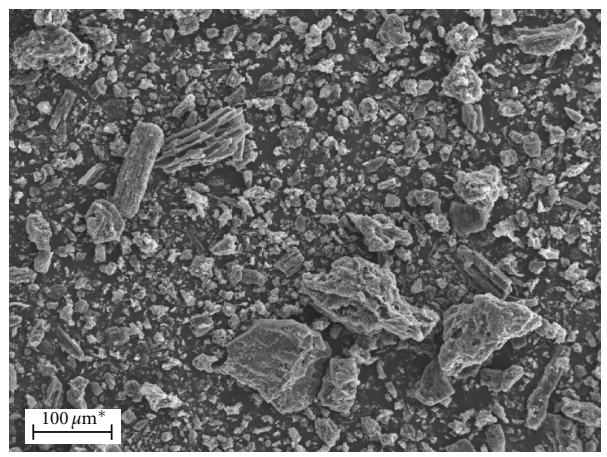

(d)

Figure 3: SEM images of (a) active carbon NORIT; (b) NiO; (c) composite W1; (d) composite W3.

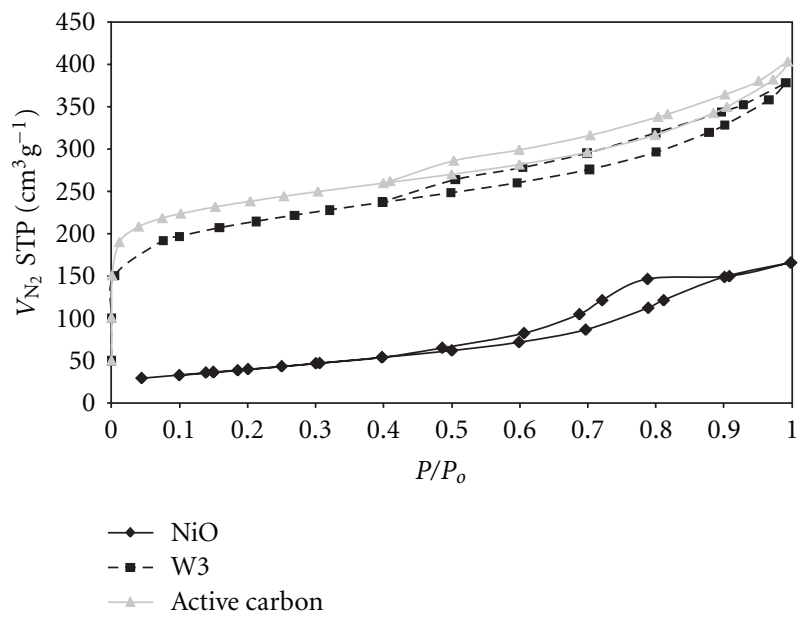

Figure 4: Nitrogen absorption/desorption isotherms of $\mathrm{NiO}$, composite $\mathrm{W} 3$, and active carbon at $77 \mathrm{~K}$.

the product burned off at $590^{\circ} \mathrm{C}$. As can be seen, the weight loss of $\mathrm{Ni}(\mathrm{OH})_{2}$ is divided into three parts: in the first up to $180^{\circ} \mathrm{C}$, the hydrated and absorbed water is removed, in the second $\left(180-320^{\circ} \mathrm{C}\right)$ the weight of hydroxide dropped due to the conversion into nickel oxide and water, and the last part of weight loss is connected with forming nonstoichiometric nickel oxides.

The morphology of composites, active carbon, and nickel oxide were examined by scanning electron microscopy. The

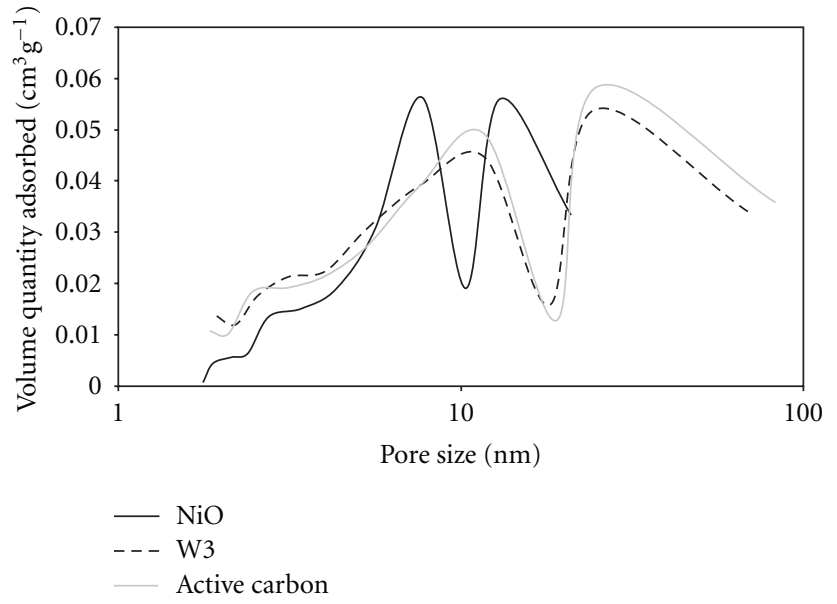

FIGURE 5: Pore-size distributions of NiO, composite W3, and active carbon.

SEM images are shown in Figure 3. The morphology of active carbon (Figure 3(a)) displays particles of a varied size with visible remaining of the precursor. The particles of $\mathrm{NiO}$ (Figure 3(b)) are characterized by quite a uniform big size with a visible small porosity. The slight difference between Figures 3(a) and 3(d) is a result of a low content of nickel oxide, and the active carbon morphology is predominant. The most noticeable difference in morphology is observed for composite $\mathrm{W} 1$ ( $34 \mathrm{wt} . \% \mathrm{NiO}$ and $66 \mathrm{wt} . \%$ 


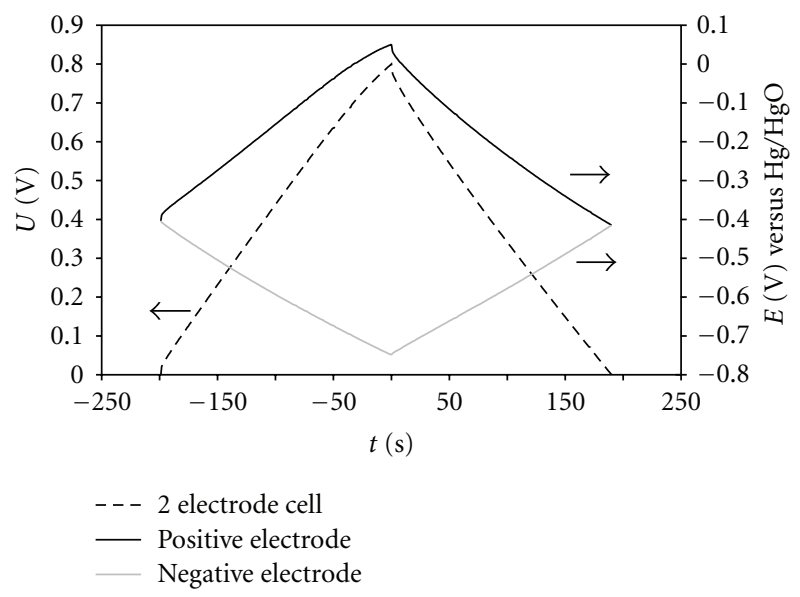

FIgURE 6: Galvanostatic charge/discharge at $200 \mathrm{~mA} / \mathrm{g}(\mathrm{C}=95 \mathrm{~F} / \mathrm{g}$ - two-electrode cell $)$ for a supercapacitor built from composite W3.

AC-Figure 3(c)), which is different from morphologies of initial materials. The particles of composite W1 have a flower-like shape. The BET surface area of $\mathrm{NiO}$ is $150 \mathrm{~m}^{2} \mathrm{~g}^{-1}$ while for AC is $776 \mathrm{~m}^{2} \mathrm{~g}^{-1}$. The composite after calcination has a higher value of the surface area than before thermal treatment with a visible increase of microporosity. After calcination, the specific surface area is $574 \mathrm{~m}^{2} \mathrm{~g}^{-1}$ (W1), $634 \mathrm{~m}^{2} \mathrm{~g}^{-1}$ (W2), and $702 \mathrm{~m}^{2} \mathrm{~g}^{-1}$ (W3). The typical nitrogen gas absorption/desorption isotherms of $\mathrm{NiO}$, active carbon, and composite W3 are shown in Figure 4. All the materials displayed an isotherm of type IV. Nickel oxide displayed the hysteresis loop of type $\mathrm{H}_{2}$, while active carbon and composite displayed the type $\mathrm{H}_{4}$ according to the IUPAC classification. The hysteresis loop-type $\mathrm{H}_{2}$ is indicative of mesoporosity, while type $\mathrm{H}_{4}$ indicates presence of microporosity. The poresize distributions of composite W3 and pristine materials calculated by $\mathrm{BJH}$ method are shown in Figure 5. It can be seen that materials have a well-developed mesopore structure.

3.2. Electrochemical Measurements. The electrochemical properties of the prepared composites were carefully investigated. The electrochemical characterization was performed in two- and three-electrode cells using $6 \mathrm{M} \mathrm{KOH}$ aqueous electrolyte. The values of capacitance for nickel oxide, active carbon, and composite $\mathrm{NiO} / \mathrm{AC}$ varied from 11 to $90 \mathrm{Fg}^{-1}$, depending on the ratio of these two components (measured at $10 \mathrm{mVs}^{-1}$ for two-electrode cell). Figure 6 presents galvanostatic charge/discharge measurements for composite W3. To establish the electrochemical nature of both electrodes, during galvanostatic measurements in twoelectrode cell, measurements of positive and negative electrodes were performed simultaneously to estimate operating voltage. The operating voltage of the positive electrode is wider than for the negative one, in spite of the fact that the capacity of the negative electrode is considerably higherFigure 7. The highest value of capacity was obtained for composite W3, ca. 20\% more than for pristine active carbon. When one compares electrochemical characteristics of the rest of the composites, there are some advantages of such electrode materials, which are shown in Figures 7 and 8. The $\mathrm{CV}$ curves for $\mathrm{AC}$ and composite material have a much more rectangular shape, which is a characteristic of a double-layer capacitive behavior. The capacity of pristine nickel oxide is low and dramatically decreases with increasing current regimes. The bare $\mathrm{NiO}$ has only pseudocapacitive properties. Figure 8 shows the dependence of capacitance on frequency in alkaline electrolyte. The drop in the value of capacitance at $1 \mathrm{~Hz}$ for composites with a lower amount of $\mathrm{NiO}$ is observed to a lesser extent in comparison to the active carbon. Composite W3 with only $7 \mathrm{wt} . \%$ of $\mathrm{NiO}$ is characterized by the highest value of capacity. It is the confirmation of the fact that such amount of nickel oxide is optimal to take advantage of both components of the composite. The active carbon plays a role of excellent conducting support for nickel oxide, which is characterized by quite big resistivity. The composite materials seem to be an excellent candidate for negative electrodes, for example, for W3 the value of capacity of negative electrode $\left(5 \mathrm{mVs}^{-1}\right.$, three-electrode cell) is $107 \mathrm{Fg}^{-1}$, whereas for the positive electrode it is only $74 \mathrm{Fg}^{-1}$. Good capacitance properties of composite W3 as electrode material have been confirmed also by impedance spectroscopy measurements-Figure 9. The value of capacity of the negative electrode is $108 \mathrm{Fg}^{-1}$, whereas for the positive electrode it is only $89 \mathrm{Fg}^{-1}$, as obtained from the impedance spectroscopy measurements for $1 \mathrm{mHz}$. ESR (equivalent series resistance) at $100 \mathrm{kHz}$ for composite $\mathrm{W} 1$ is $0.340 \Omega$, for W2 is $0.298 \Omega$, and for W3 is $0.277 \Omega$ and confirms that active carbon has capacitance mainly from a double layer, whereas nickel oxide/active carbon has both the characteristic from the double layer and from the surface redox-type reactions. It clearly shows a beneficial conducting role of active carbon with probably a good type of electronic transport.

The application of an asymmetric configuration with materials of different nature is advisable because of the possibility of increasing the operating voltage in aqueous solution, which affects the power and energy of supercapacitors. Direct chemical precipitation of nickel hydroxide on active carbon seems to be a good method to obtain a composite material. 


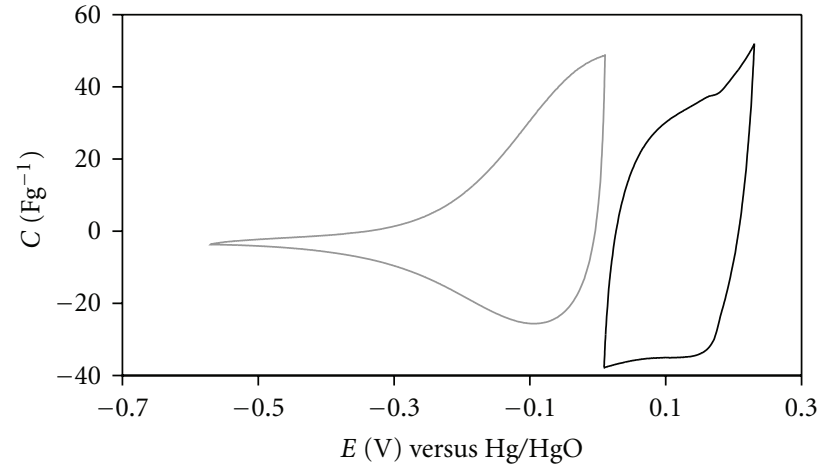

(a)

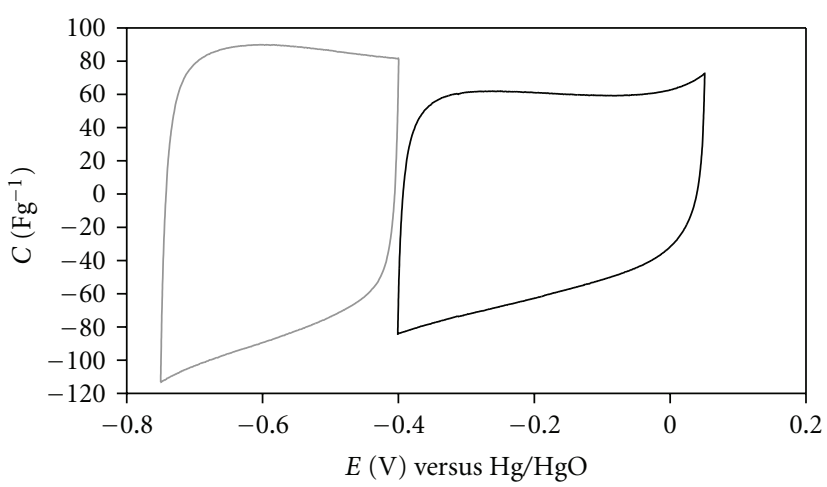

(c)

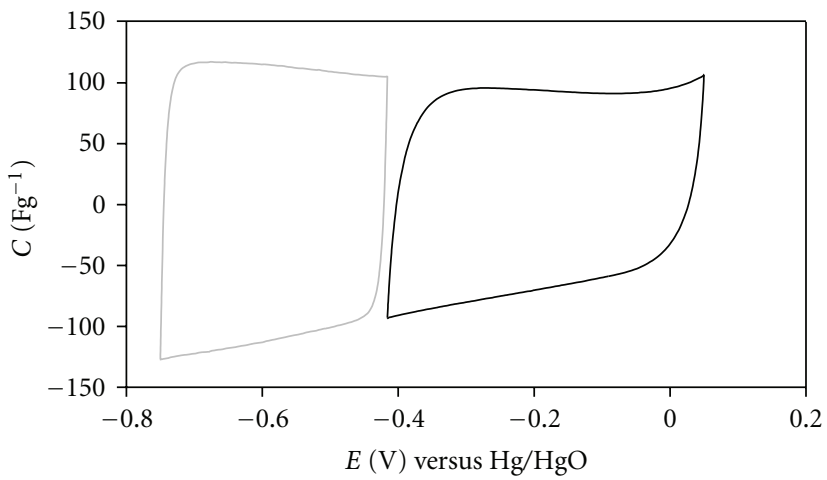

Negative electrode

— Positive electrode

(e)

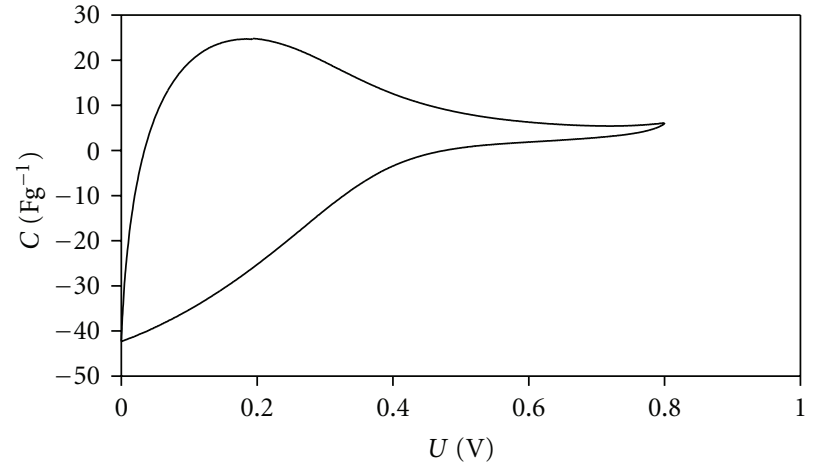

(b)

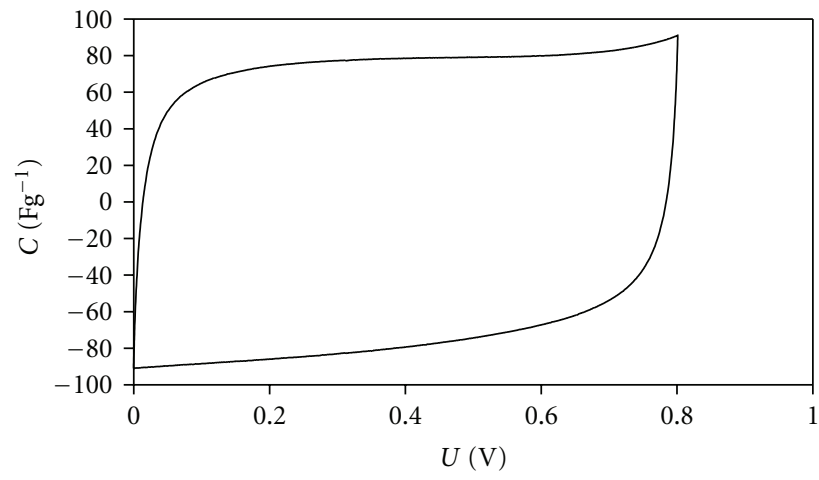

(d)

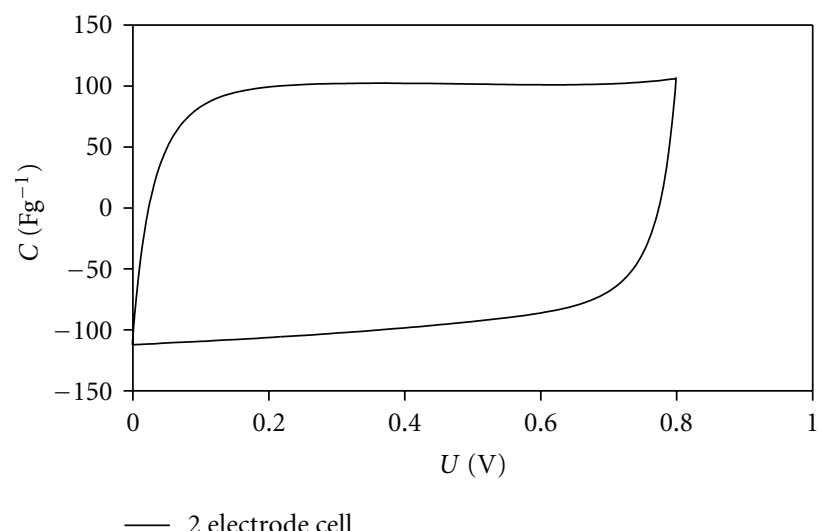

(f)

Figure 7: Voltammetry characteristics of $\mathrm{NiO}(\mathrm{a}, \mathrm{b})$; AC (c, d); composite W3 (e, f). The CV (b, d, f) are made in a two-electrode Swagelok system at a scan rate $10 \mathrm{mV} / \mathrm{s}$, while curves $(\mathrm{a}, \mathrm{c}, \mathrm{e})$ are made in a three-electrode Swagelok system at a scan rate of $5 \mathrm{mV} / \mathrm{s}$.

The process of annealing at $300^{\circ} \mathrm{C}$ allows converting nickel hydroxide into nickel oxide. This kind of composite can play a role of an excellent negative electrode for asymmetric capacitors.

\section{Conclusion}

The method of chemically precipitating nickel hydroxide and the temperature of calcination process allows obtaining a composite material with quite good capacitance properties.
To establish the electrochemical nature of the composite, investigations in two- and three-electrode systems were carried out. The composite with a low amount of nickel oxide seems to be an excellent solution as a negative electrode. It was confirmed that such an amount of nickel oxide is optimal to take advantage of both components of the composite, then capacitance comes from the combination of the doublelayer capacitance of active carbon and pseudocapacitance associated with the surface redox-type reactions. The active carbon plays a role of an excellent conducting support for nickel oxide, which is characterized by quite big resistivity. 


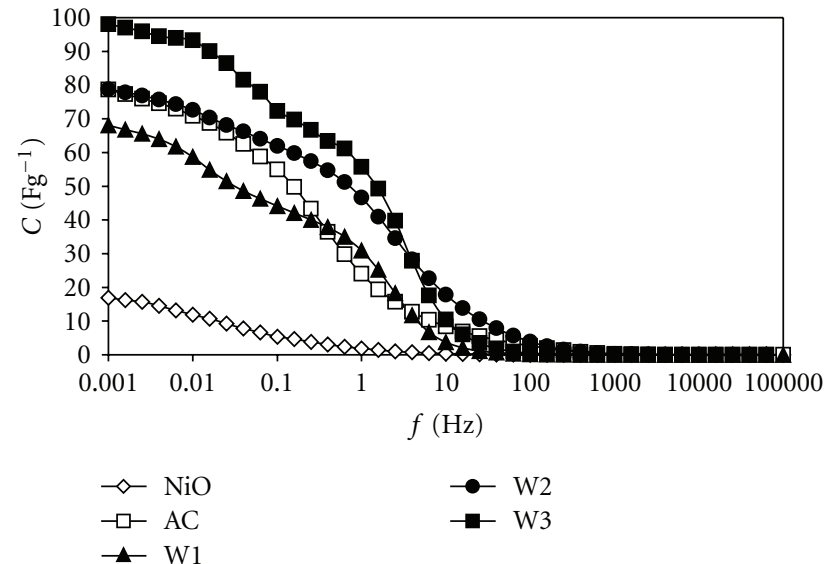

FIGURE 8: Capacitance versus frequency for supercapacitors built from $\mathrm{NiO}, \mathrm{AC}$, and composites $\mathrm{NiO} / \mathrm{AC}$.

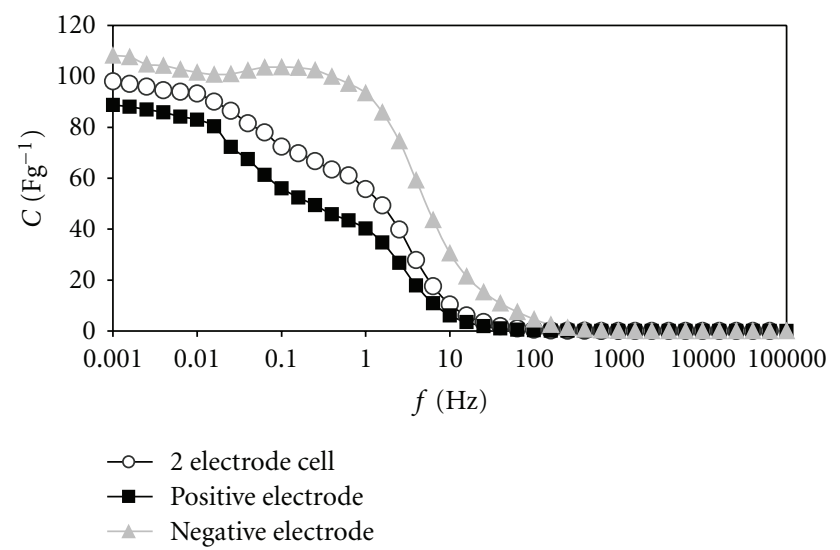

FIGURE 9: Capacitance versus frequency for a supercapacitor built from composite W3 in a two- and three-electrode cell.

The electrochemical investigations show that composite nickel oxide/active carbon needs further investigations as a negative electrode in asymmetric configuration of electrode materials in electrochemical capacitors.

\section{Acknowledgment}

The authors acknowledge the financial support from the Ministry of Science and Higher Education (Poland) under Grant no. N N205 012334.

\section{References}

[1] G. Lota, T. A. Centeno, E. Frackowiak, and F. Stoeckli, "Improvement of the structural and chemical properties of a commercial activated carbon for its application in electrochemical capacitors," Electrochimica Acta, vol. 53, no. 5, pp. 2210-2216, 2008.

[2] CH. Emmenegger, PH. Mauron, P. Sudan et al., "Investigation of electrochemical double-layer (ECDL) capacitors electrodes based on carbon nanotubes and activated carbon materials," Journal of Power Sources, vol. 124, no. 1, pp. 321-329, 2003.
[3] B. Fang and L. Binder, "A modified activated carbon aerogel for high-energy storage in electric double layer capacitors," Journal of Power Sources, vol. 163, no. 1, pp. 616-622, 2006.

[4] D. Rochefort and A.-L. Pont, "Pseudocapacitive behaviour of $\mathrm{RuO}_{2}$ in a proton exchange ionic liquid," Electrochemistry Communications, vol. 8, no. 9, pp. 1539-1543, 2006.

[5] E. Frackowiak, V. Khomenko, K. Jurewicz, K. Lota, and F. Béguin, "Supercapacitors based on conducting polymers/nanotubes composites," Journal of Power Sources, vol. 153, no. 2, pp. 413-418, 2006.

[6] G.-H. Yuan, Z.-H. Jiang, A. Aramata, and Y.-Z. Gao, "Electrochemical behavior of activated-carbon capacitor material loaded with nickel oxide," Carbon, vol. 43, no. 14, pp. 29132917, 2005.

[7] Q. Huang, X. Wang, J. Li, C. Dai, S. Gamboa, and P. J. Sebastian, "Nickel hydroxide/activated carbon composite electrodes for electrochemical capacitors," Journal of Power Sources, vol. 164, no. 1, pp. 425-429, 2007.

[8] J. Cheng, G.-P. Cao, and Y.-S. Yang, "Characterization of solgel-derived NiOx xerogels as supercapacitors," Journal of Power Sources, vol. 159, pp. 734-741, 2006.

[9] J. Y. Lee, K. Liang, K. H. An, and Y. H. Lee, "Nickel oxide/carbon nanotubes nanocomposite for electrochemical capacitance," Synthetic Metals, vol. 150, no. 2, pp. 153-157, 2005.

[10] K.-W. Nam, W.-S. Yoon, and K.-B. Kim, "X-ray absorption spectroscopy studies of nickel oxide thin film electrodes for supercapacitors," Electrochimica Acta, vol. 47, no. 19, pp. 3201-3209, 2002.

[11] K.-W. Nam, K.-H. Kim, E.-S. Lee, W.-S. Yoon, X.-Q. Yang, and K.-B. Kim, "Pseudocapacitive properties of electrochemically prepared nickel oxides on 3-dimensional carbon nanotube film substrates," Journal of Power Sources, vol. 182, no. 2, pp. 642-652, 2008.

[12] M.-S. Wu and H.-H. Hsieh, "Nickel oxide/hydroxide nanoplatelets synthesized by chemical precipitation for electrochemical capacitors," Electrochimica Acta, vol. 53, no. 8, pp. 3427-3435, 2008.

[13] M. Wu, J. Gao, S. Zhang, and A. Chen, "Comparative studies of nickel oxide films on different substrates for electrochemical supercapacitors," Journal of Power Sources, vol. 159, pp. 365369, 2006.

[14] V. Srinivasan and J. W. Weidner, "Studies on the capacitance of nickel oxide films: effect of heating temperature and electrolyte concentration," Journal of the Electrochemical Society, vol. 147, no. 3, pp. 880-885, 2000.

[15] Y. -z. Zheng, H. -y. Ding, and M. -l. Zhang, "Preparation and electrochemical properties of nickel oxide as a supercapacitor electrode material," Materials Research Bulletin, vol. 44, no. 2, pp. 403-407, 2009.

[16] D.-W. Wang, F. Li, and H.-M. Cheng, "Hierarchical porous nickel oxide and carbon as electrode materials for asymmetric supercapacitor," Journal of Power Sources, vol. 185, no. 2, pp. 1563-1568, 2008.

[17] V. Ganesh, S. Pitchumani, and V. Lakshminarayanan, "New symmetric and asymmetric supercapacitors based on high surface area porous nickel and activated carbon," Journal of Power Sources, vol. 158, no. 2, pp. 1523-1532, 2006. 


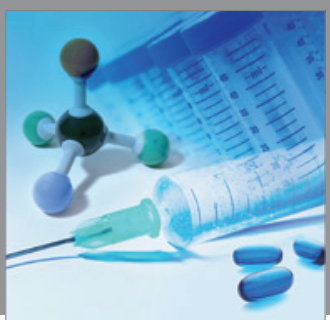

International Journal of

Medicinal Chemistry

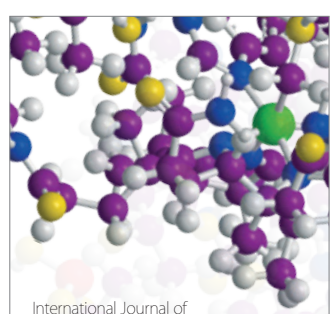

Carbohydrate Chemistry

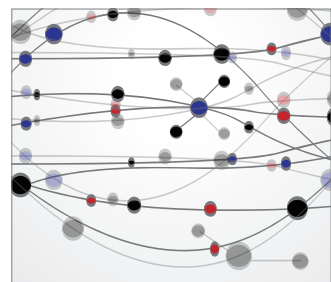

The Scientific World Journal
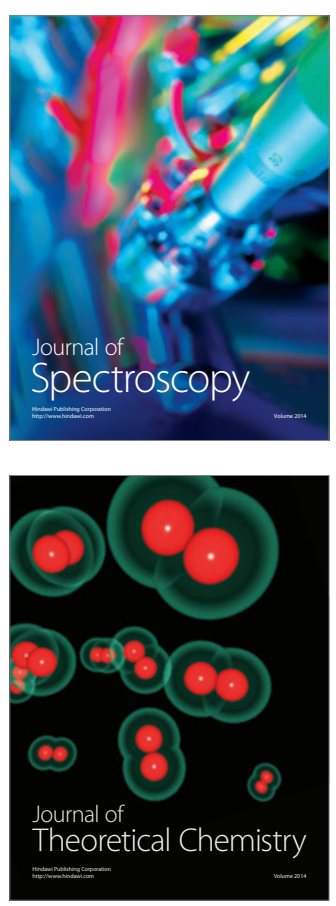
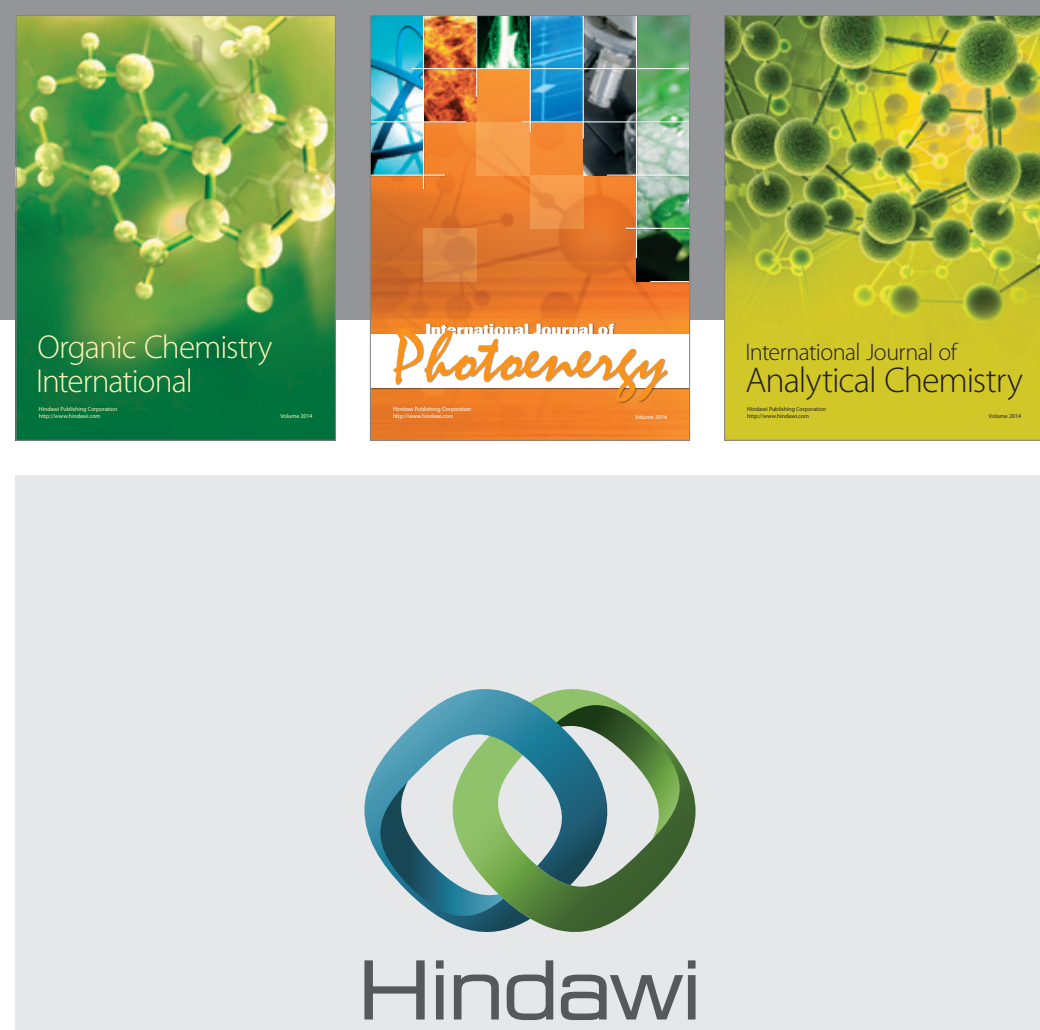

Submit your manuscripts at

http://www.hindawi.com
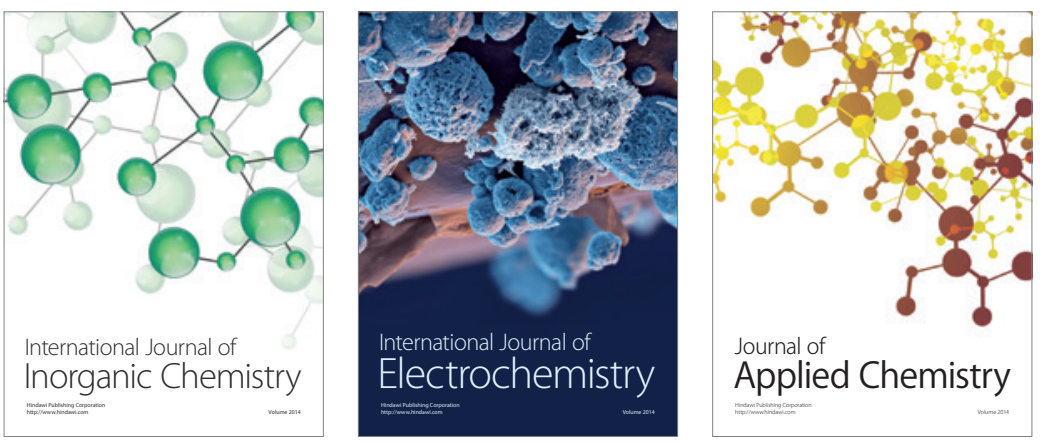

Journal of

Applied Chemistry
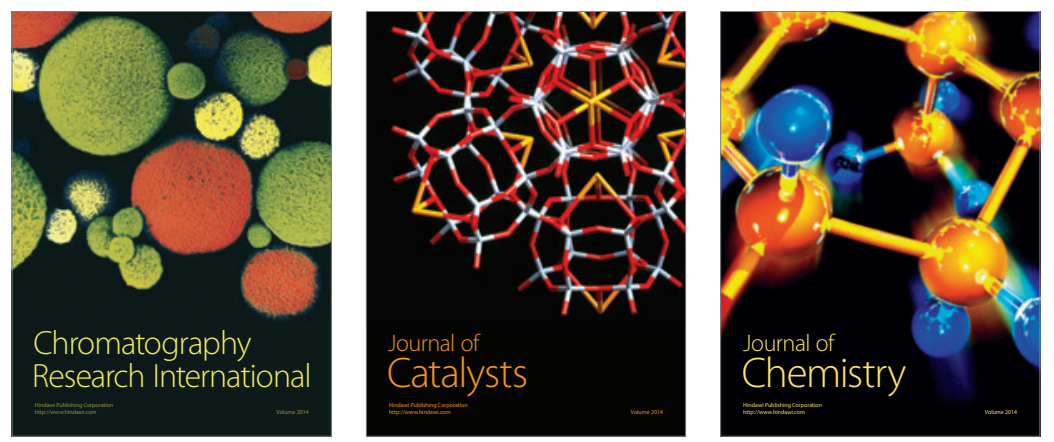
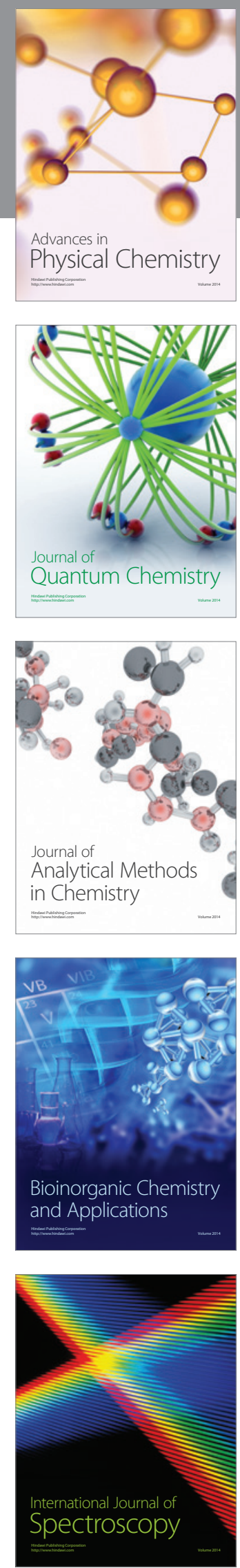